\title{
THEORETICAL INVESTIGATION OF INCREASING EFFICIENCY OF COMBINE HARVESTER OPERATION ON SLOPES
}

\author{
Alexandr Belinsky, Bulat Ziganshin, Ayrat Valiev, Damir Haliullin, Ilgiz Galiev, Nail Adigamov \\ Kazan State Agrarian University, Russia
}

ayratvaliev@mail.ru,zigan66@mail.ru,damirtag@mail.ru,drgali@mail.ru,n-adigamov@rambler.ru

\begin{abstract}
Intensification of work processes of agricultural machinery is a part of important national economic problems of increase of agricultural production. One way to increase intensity is to reduce grain loss when working with combine harvesters on slopes of fields. In the lateral pitch of the harvester there is redistribution of the grain heap on the screen width and cleaning sieves. The diagram of linear distribution density of the grain heap on the screen width and cleaning sieves is transformed from a uniform type of rectangle to irregular: the type of triangle, trapeze without a shift or with a shift in the direction of the pitch. We have large losses of grain, because of the uneven linear distribution density of the grain heap on the screen width and sieves. The article offers various methods and devices, which have certain advantages and disadvantages, to reduce grain loss. One of the promising directions to reduce grain loss is the dynamic method, which uses a specific device as a set of hinged-lever units. However, one of the major drawbacks of these devices is the equality of oscillation frequency of the longitudinal and lateral pitch. The adopted working hypothesis and studies of the process kinematics and dynamics will define the main structural and technological parameters of the cam mechanism to align the linear distribution density of the grain heap on the screen width and sieves.
\end{abstract}

Keywords: grain heap, traffic density, alignment of distribution density, cam mechanism.

\section{Introduction}

The efficiency of combine harvesters mostly depends on the field topography. The combine productivity decreases due to uneven loading of the cleaning system, when working on slopes greater than $2^{\circ}$. Thus, on a slope of $5^{\circ}$, the combine harvester loses up to $3.5 \%$ of grain, and the cleaning system accounts for about $60 \%$ of all losses. The combine productivity reduces so that to reduce the loss of grain when working on slopes. If on a plain the combine productivity is taken equal to $100 \%$, then on a slope of $5^{\circ}$ it decreases to $83 \%$, and on a slope of $9^{\circ}-$ to $63 \%$ [1].

Intensification of the working process of agricultural machinery is part of the important issue of increasing crop production. The existing theories of agricultural machines and, in general, agricultural mechanics use various models (mental and physical) with a certain degree of idealization of the actual operating conditions for various tasks, associated with creation and improvement of agricultural machinery $[1 ; 2]$.

An important indicator that characterizes the workflow of agricultural machinery is the intensity Int (from Latin "Intense") of material movement of dimension $\mathrm{kg} \cdot \mathrm{s}^{-1} \cdot \mathrm{m}^{-2}[3]$.

One of the ways of intensification of the work processes of combine harvesters is to reduce losses, occurring in the course of work, such as cleaning the combine at its pitches. The research on the assessment and prediction of the total losses of grain, according to the various settings using the regression analysis and neuro-fuzzy model, showed a high determination coefficient, which is considerably exceeding the values obtained by other methods [4]. The possibilities of increment of grain harvester efficiency by the example of corn harvesting was studied [5]. A model of workflow dynamics with curves of the grain selection intensity on the length of the working unit was designed, which allows to determine the parameters to reduce grain losses during harvesting with combines [6]. The impact of technological and kinematic parameters during the passage of the cut grain mass through the working units of the combine to reduce losses and their minimization were studied [7].

Automatic leveling of the combine with pitch by turning the final drive of the running gear [8], using the hinge four-units on the drive bridge of wheels and the hydraulic cylinders on the guiding bridge of wheels is described [9].

Alignment of the screen, cleaning sieve into a horizontal position in the lateral pitch is done using a gyroscope, hydraulic cylinder, hinge double-crank arm [10], or by using a gyroscope, hydraulic cylinder, hinged-lever mechanism [11]. The bottom of the screen is divided longitudinally into five parts, each of which rests on a hinge, mounted on the frame of screen. In the lateral pitch all five parts of the bottom take a horizontal position at the same time [12;13]. 
Automatic alignment of the thickness of the grain heap layer in the lateral pitch of the combine by the dynamic method is performed by a hinged-lever [14], crank arm device [15].

To increase the capacity of the grain heap, there are researches on improving the design of the airsieve cleanings, as well as devices that improve their work. By separation of the air flow, generated by the fan, the top stream blows the heap layer on the output from the screen, the second stream blows the heap layers of the top and bottom sieves [16].

One of the promising directions of alignment of distribution density of the grain heap at cleaning is the dynamic method and devices, providing a joint lateral movement of the grain heap with screen cleaning up the roll and sliding screen with respect to the grain heap when driving down the roll.

The purpose of the study is theoretical determination of the main structural and technological parameters of the cam gear of the combine cleaning system for leveling the density of the linear distribution of the grain heap across the width of the riddle and the screens, as well as analyzing the kinematics and dynamics of the process.

\section{Materials and methods}

Physical and mechanical properties of the grain heap parameters are threshing, separation mechanism and cleaning.

The displacement of the diagram of linear density distribution between the combs of the screen occurred in the lateral pitch of the combine harvester, to the left or right, in fall of the heap particles from the concave of the threshing machine on the screen of cleaning. It is more convenient to use the following formula with of the mass traffic intensity through the working units of combine harvesters:

$$
I=q \cdot S^{-1},
$$

where $q$-supply (consumption), $\mathrm{kg} \cdot \mathrm{s}^{-1}$;

$S$-cross-sectional area of the moving mass, $\mathrm{m}^{2}$.

As it can be seen from the formula, the intensity of the work process affects the parameters: supply of mass $q$ and the cross sectional area of the moving mass $S$. Increase in the intensity of the work process can be achieved by increasing the numerator of the formula, or reducing the denominator. The dependence of the moving mass intensity on the supply (consumption) with a constant cross-sectional area of the moving mass is straight (see Figure 1). It is the equation of line of the following form:

$$
y=x \cdot k q,
$$

where $k q$-slope of intensity of the moving mass, $k q=1 / S$.

The dependence of the $I$ move intensity on the cross-sectional area $S$ of the moving mass (see Fig. 1) is hyperbolic - it is the equation of the form:

$$
y=k S / x,
$$

where $k S-$ constant intensity factor.

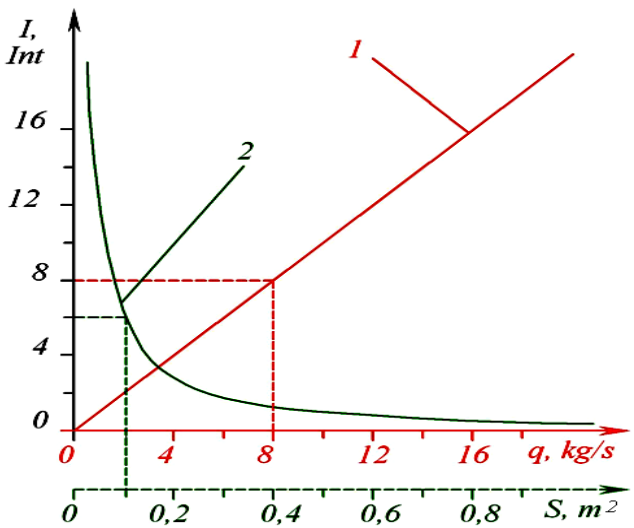

Fig. 1. Diagrams of dependence of material moving intensity: $1-$ on supply $\mathrm{kg} \cdot \mathrm{s}^{-1}$; 2 - on cross-sectional area $\mathrm{m}^{2}$ 
The numerical values of the mass moving intensity through the working units of cleaning of combine harvesters [2] with the reaper width of $6 \mathrm{~m}$, productivity of grain $0.4 \mathrm{~kg} \cdot \mathrm{m}^{-2}$, grain weight ratio to the weight of the straw $1: 1.5$, operating speed of $2 \mathrm{~m} \cdot \mathrm{s}^{-1}$, to loading of grain $q_{g}=4 \mathrm{~kg} \cdot \mathrm{s}^{-1}$ vary widely: from 0.174 Int on the separation of grain through the straw walker up to the 1076 Int on the delivery screw conveyer.

The intensity of grain separation through the concave of the threshing machine and through the straw walker differs by 12 times, and the mass moving intensity through the straw chopper is 2 times higher than the cutting apparatus of higher reapers. The grain mass moving intensity is 1.4 times higher at the outlet of the threshing apparatus than at its inlet.

During the lateral pitch the diagram of linear density distribution and displacement $\Delta i$ of higher grain heap in higher width between combs of higher screen toward the lateral pitch (see Figure 2) was changed because of falling grain heap components from different heights of the deck: from a maximum height of the deck $H_{\max }$ to the value of $\Delta 2$, from a lower deck height to $H_{\min }$ - to $\Delta 1$.

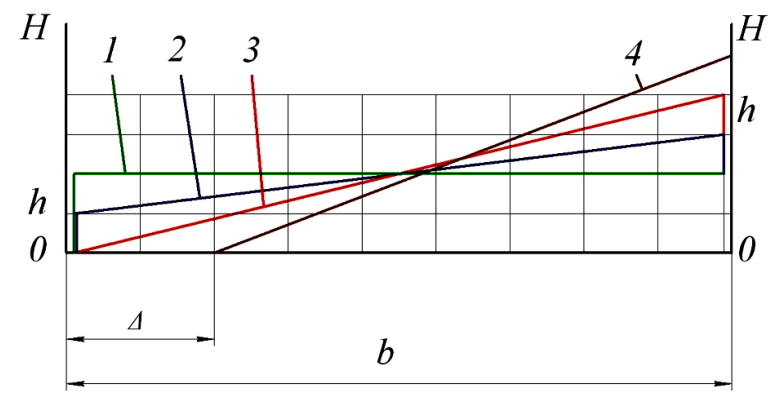

Fig. 2. Dynamics of changes in diagrams of linear density distribution of grain heap across width at lateral pitch: from the $1^{\text {st }}$ diagrams of $A$ type to the $2^{\text {nd }} B$ type then to the $3^{\text {rd }} \mathrm{C}$ type, then to the $4^{\text {th }}$ diagram of 4-type with offset value $\Delta$

In the absence of the lateral pitch: A diagram of distribution of A - rectangle type. In the way of lateral pitch there is redistribution: for small angles of heel from type A to type B - unequal trapeze, for medium angles of heel from type $\mathrm{B}$ to type $\mathrm{C}$ - right triangle, for large angles of heel from type $\mathrm{C}$ to type $\mathrm{D}$ - right triangle with removal of comb base by $\Delta$ value. Also other variants of either type or combination of different types are possible.

There is also a shift of $\Delta i$ diagram of linear distribution density across the width of a possible grain heap screen because of the $H_{\text {gr }}$ height of a possible screen comb. As a result, we have a nonuniform thickness of $\mathrm{H}_{\text {slv }}$ of a possible grain heap on the screen width.

As formation of diagrams of the linear distribution density of possible grain heaps in width between screen combs of cleaning is random, so the concrete diagram (see Figure 2) may be of one of several possible options for distribution of possible types: A, B, C or D. In the way of diagram distribution of $\mathrm{C}$ type the pressure of the air flow from the bottom at an angle up on possible grain heap will be uneven, as the most of the air flow rushes toward the lower resistance, i.e. there, where there is a less thickness of the grain heap.

Primarily two factors influence on the parameters of the linear distribution density: the type of the distribution diagram and the amount of displacement of distribution diagrams from the base of the ridge in the fall of heap particles from the concave of the threshing machine on the cleaning screen. Removal of the diagram from the base of the ridge depends on the height of incidence and angle of heel, and is as follows: when a fall is a height of $H_{\max }=0.5 \mathrm{~m}$, the offset is $\Delta i=0.5 \operatorname{tg} 100=0.0881 \mathrm{~m}$, or about $30 \%$ of the distance between the combs $b$, when a fall is a height $H_{\min }=0.1 \mathrm{~m}$, the offset is $\Delta i=0.1 \operatorname{tg} 100=0.0176 \mathrm{~m}-$ it is about $7 \%$ of the distance between the combs. These examples show that the displacement of distribution diagrams from the base of the comb falling point substantially depends on the pitch of the combine and requires quantitative assessment of the unevenness of the linear distribution density of the grain heap across the width of the screen. When A-type distribution has $h_{\text {average }}=10 \mathrm{~mm} ; \sigma= \pm 0.00 \mathrm{~mm}$; the coefficient of variation (unevenness) is $v= \pm 0.00 \%$. At Btype distribution the unevenness of the grain heap distribution across the width of the screen depends on the heap layer thickness of the left and right combs. In the absence of removal, i.e. $\Delta=0$, and in the change of the layer thickness ratio of the grain heap of the left comb to the thickness of the right comb 
from 1.0 to 0.1 , the unevenness of distribution increases from $v= \pm 0.00 \%$ to $v= \pm 39.97 \%$. The C-type distribution has the following parameters of the grain heap distribution across the width of the screen: $h_{\text {average }}=10.0 \mathrm{~mm}, \sigma= \pm 3.99 \mathrm{~mm}, v= \pm 39.97 \%$. The parameters of the D-type linear distribution density of the grain heap at displacement $\Delta=4 \mathrm{~cm}$ are the following: value $h_{\text {average }}=9.913 \mathrm{~mm}, \sigma= \pm 6.895 \mathrm{~mm}, v= \pm 69.5 \%$. The parameters of the grain heap distribution across the width of the screen of the D-type distribution depend on the magnitude of the displacement $\Delta$ of the density diagram distribution from the screen comb. In the above examples the coefficient of variation has changed the values from $v= \pm 67.50 \%$ to $v= \pm 119.57 \%$.

\section{Results and discussion}

The power analysis was used to equalize the distribution density of the grain heap in cleaning, which was based on the laws of agricultural mechanics, including the mechanics laws of Newton.

The particle of heap, located on the screen at rolling of the combine on a cross-vertical area, is acted by the following forces: gravity $G=m g$, inertia $P J=m j$, friction $F=N G \cdot f=N G \cdot \operatorname{tg} \varphi$, the normal reaction of screen.

$N G=G n$ is the tangential component of gravity $G T=G \sin \alpha$. The analysis of operating forces on a particle on rolling is made without forces acting on a longitudinal vertical area, because their projection on a cross-vertical surface is equal to zero.

The working hypothesis. It is necessary to keep at least two conditions for leveling the distribution density of the grain heap layer in cleaning on the combine rolling: the joint motion of the heap with a screen while roll driving up and glide of the heap up relative to the sieve while roll driving the sieve down.

The satisfaction of the first condition of the working hypothesis about the joint motion of the heap with a screen while roll driving up (see Figure 3 ) is expressed by the dependence:

$$
F \geq G T+P,
$$

where $F$ - frictional force of an element on the surface of the screen, $N$;

$G T$ - tangential component of gravity of the element, N;

$P$ - force of inertia of the element, N.

$A$

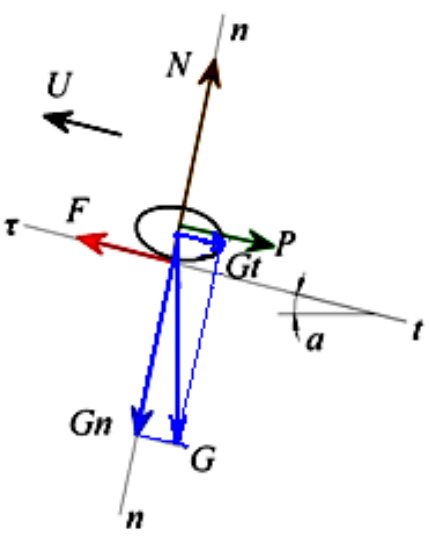

$B$

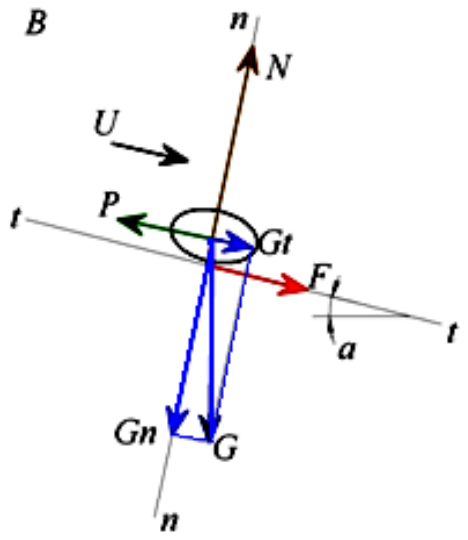

Fig. 3. Scheme for power analysis of interaction of elements with screen on rolling of combine

harvester: $\mathrm{A}$ - in the way of rolling accelerated motion of the sieve up. B - in the way of rolling accelerated motion of the sieve down

Satisfaction of the second condition of the working hypothesis about slipping the sieve down regarding the heap, when roll driving of the sieve down is represented by the formula:

$$
P>G T+F \text {. }
$$

The analysis of the formulas follows that the crucial force of leveling in the mentioned interaction is the force of inertia, the numerical value of which depends on the element's mass and acceleration. After substituting in the formula the meanings and transformations, we obtain new matters of joint motion of the heap with a screen while roll driving up and sliding down the screen relative to the heap, 
when roll driving a sieve down, expressed by critical values of the lateral acceleration of the sieve up and down in the way of roll. The critical values of lateral acceleration of the screen up for roll harvesting different crops:

$$
j_{c r} u \leq g(\cos \alpha \cdot \operatorname{tg} \varphi-\sin \alpha),
$$

where $j_{c r} u$-critical value of lateral acceleration of the screen up on the roll, $\mathrm{m} \cdot \mathrm{s}^{-2}$;

$g$ - earth gravity acceleration, $\mathrm{m} \cdot \mathrm{s}^{-2}$;

$\alpha$ - angle of the lateral pitch, 0 ;

$\varphi$ - dynamic friction angle of grain on the surface of the sieve, 0 .

and down:

$$
j_{c r} d \leq g(\cos \alpha \cdot \operatorname{tg} \varphi+\sin \alpha),
$$

where $j_{c r} d$-critical value lateral acceleration of the screen down on the roll, $\mathrm{m} \cdot \mathrm{s}^{-2}$.

An indication of the kinematic mode of equalizer is the ratio of the critical value of lateral acceleration of the screen down on rolling to the critical value of lateral acceleration of the screen on rolling:

$$
\varepsilon=\frac{t_{d}}{t_{u}}=\left[\frac{j_{c r} d}{j_{c r} u}\right]^{-0.5},
$$

where $\varepsilon$-index of kinematic mode of equalizer;

$t_{d}$ - time of lateral movement of the screen down on roll, s;

$t_{u}$ - time of lateral movement of the screen up on roll, s.

We come to the following formulation from the analysis of critical values of lateral acceleration of the screen, sieve: first, the rolling motion of the screen, sieve up from one extreme position to the other occurs at a constant value of acceleration on the linear dependence; secondly, the numerical values of the velocity vectors vary from zero to a maximum for the linear dependence. The rolling motion of the screen, sieve down from one extreme position to the other occurs at a constant value of acceleration on the linear dependence; secondly, the numerical values of the velocity vectors vary from zero to a maximum for the linear dependence.

On average, the angle of steel friction of cereal crops is about $\varphi=18 \ldots 30^{\circ}$. The maximum value of an angle side roll of the combine to equalize the thickness of the grain heap layer is limited by the maximum values of the friction angle of seeds; otherwise there will be a spontaneous slide down roll of the material.

\section{Density parameters of grain heap distribution across the width}

The density parameters of the grain heap distribution across the width of the screen, sieve of the combine harvester are: the arithmetic mean of the thickness $h_{\text {average, }}$ the standard deviation $\sigma$, the unevenness of the distribution density across the width $v$. Some examples of calculations for the distributions of A, B, C and D type are presented in Table 1 for comparison.

Table 1 shows that the unevenness of distribution of the grain heap particles across the width of the shook board of cleaning on the roll of the combine increased from $0 \%$ to $119 \%$.

Table 1

Parameters of the linear distribution density across the width at the combs step of $23 \mathrm{~cm}$, class interval $1 \mathrm{~cm}$, quantity of classes 23

\begin{tabular}{|c|c|c|c|c|}
\hline Distribution types & A & B & C & D \\
\hline $\begin{array}{c}\text { Arithmetic mean of } \\
\text { thickness } h_{\text {average }}, \mathrm{mm}\end{array}$ & 10.0 & 10.0 & 20.1 & 1004 \\
\hline Standard deviation $\sigma, \pm \mathrm{mm}$ & \pm 0.00 & $\pm 0.00 \ldots 1.29$ & \pm 11.9 & \pm 675 \\
\hline Constant of variation $v, \pm \%$ & \pm 0.0 & $\pm 0.0 \ldots 39.7$ & $\pm 39.7 \ldots 589$ & $\pm 589 \ldots 1199$ \\
\hline
\end{tabular}


The devices for leveling the linear distribution density of the grain heap on screen cleaning at the roll of the harvester.

A variety of methods and devices are offered for aligning the linear distribution density of the grain heap on screen cleaning at the roll of the harvester. The most interesting of these is the dynamic method for compensating of the combines' roll [14], the principle of operation of which is concluded in additional oscillatory motions of sieves, directed to the top of the slope. The power and direction of the oscillatory motions depend on the steepness of the slope and position of the combine.

The analysis of the forces, operating on the particle and modes of operation of sieves of the mentioned systems, follows that because of the relatively small values of the kinematic mode of equalizer close to 1.20 , they are useful for smoothing the distribution density of the grain heap across the width of the screen and cleaning for small values of lateral roll of the harvester $(2 \ldots 3 \%)$.

The observance of two conditions, namely: joint motion of the heap with a screen while roll driving up and slide the sieve down with respect to the heap when driving the sieve down at the roll more than $3 \%$ provides a cam equalized of the grain heap distribution density [15]. The cam profile allows to get the necessary laws (diagrams of velocities and accelerations) of lateral movement of the screen at roll of the combine.

We can obtain the necessary laws (diagrams) of lateral movement of the screen at the roll of the combine on the basis of the cam mechanism. A cam device is one of the solutions to solve the abovementioned problem [15].

Table 2

\section{Estimated values of kinematic mode of equalizer of heap layer for harvesting wheat and lateral roll harvester}

\begin{tabular}{|l|c|c|c|c|c|}
\hline Angle of roll, $\boldsymbol{\alpha}, \boldsymbol{\%}$ & $\mathbf{0}$ & $\mathbf{5}$ & $\mathbf{1 0}$ & $\mathbf{1 5}$ & $\mathbf{2 0}$ \\
\hline Critical acceleration down $j_{c r} d, \mathrm{~m} \cdot \mathrm{s}^{-2}$ & 3.96 & 4.80 & 5.61 & 6.37 & 7.08 \\
\hline Critical acceleration up $j_{c r} u, \mathrm{~m} \cdot \mathrm{s}^{-2}$ & 3.96 & 3.09 & 2.20 & 1.29 & 0.37 \\
\hline Kinematic mode $\varepsilon=\left[j_{c r} d /\left(j_{c r} u\right)\right]^{-0.5}$ & 1.00 & 1.24 & 1.60 & 2.22 & 4.37 \\
\hline
\end{tabular}

Figure 4 shows graphs of dependence of the values of the kinematic mode of equalizer of the heap layer $\varepsilon$ on the angle of lateral pitch $\alpha$ during peas, oats and wheat harvesting. The analysis of the graphs presents that when harvesting wheat the angle of the lateral pitch $\alpha$ increases from $0 \%$ to $4 \%$ and it has almost no effect on the value of the index of the kinematic mode of vibration of the sieve $\varepsilon$, increases from 1.00 to 1.09 .

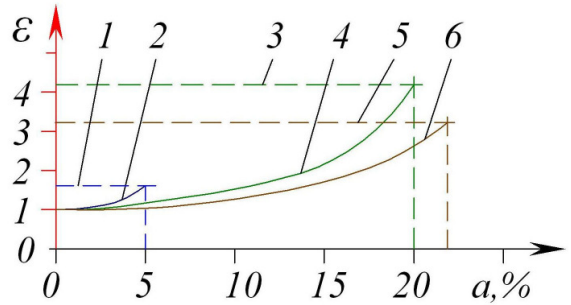

Fig. 4. Graphs of dependence of kinematic mode of equalizer of heap layer on angle of roll at harvest of peas, oats, wheat: $1,3,5$ - minimum values of indicators of the kinematic mode of equalizer, respectively, peas, oats, wheat; Graphs 2, 4, 6 of dependence $\varepsilon=f(\alpha)$, respectively, of peas, oats, wheat

But it is required to increase the value of the kinematic mode of the sieve vibrations to a value $\varepsilon=1.25$, when the rolling value is $5 \%$.

A further increase of the roll from $10 \%$ to $20 \%$ requires an increase in the index of the kinematic mode of vibration of the sieve from 1.60 to 4.37. The calculations show that an increase in the roll from $20 \%$ to $25 \%$ requires a change in the direction of acceleration to the contrary, which is equal to an average of 0.41 for a given coefficient of friction on steel of millet. When harvesting oats, the increase of roll over $20 \%$ requires a change in the direction of acceleration to the contrary, but this 
method does not provide the alignment of the layer on the screen and sieve, because of the dynamic coefficient of friction of millet on the steel surface, which is equal to an average of 0.41 .

\section{Conclusions}

1. The accepted working hypothesis for the study of kinematics and dynamics of the process allows determining the main structural and technological parameters of the cam gear for equalizing the density of the linear distribution of the grain heap across the width of the riddle and the screens.

2. By increasing the lateral pitch of the harvester a gradual redistribution occurs of the grain heap down for cleaning on the roll with the linear distribution density type A to type B, then to type $\mathrm{C}$, then to type $\mathrm{D}$, depending on the magnitude of the roll angle.

3. Alignment of the linear density of distribution with rolls of more than $3 \%$ is achieved by the joint movement of the pile with the roar when moving up the list and sliding of the sieve relative to the pile down the list, provided by the cam gear, which allows to obtain the necessary kinematic modes of operation $\varepsilon$, for example, when harvesting wheat or oats: from the value of $\varepsilon=1.24$ at a list of $5 \%-$ to $\varepsilon=4.37$ at a list of $20 \%$. The intensity of the combine when the list $5 \%$ increases by $17 \%$ and when $10 \%$ - to $37 \%$.

4. The limiting values of the list to obtain the required kinematic operation mode $\varepsilon$ to align the linear distribution density depend on the physical and mechanical properties of the ccrop, so, when harvesting peas, this is a list of $5 \%$ with $\varepsilon=1.23$.

\section{References}

[1] Гурьев Е.А. Исследование возможностей интенсификации технологического процесса очистки зерноуборочного комбайна (Investigation of possibilities of intensification of technological process of a combine harvester clearing). Abstract of dissertation for the degree of $\mathrm{PhD}$ of technical sciences. Omsk, 1974. 25 p. (In Russian).

[2] Лурье А.Б. Статистическая динамика сельскохозяйственных агрегатов (Statistical dynamics of agricultural units). M .: Kolos, 1981. 382 p. (In Russian).

[3] Белинский А.В, Милюкова М.А. Интенсификация рабочих процессов мобильных сельхозмашин (The intensification of agricultural mobile workflows). Tractors and farm machinery. 2000, No 9, pp. 34-35. (In Russian).

[4] Zareei S., et all., Regression and Neuro-Fuzzy Models for Prediction of Combine Header Loss. Iveco Jornal of Science and Technology, vol.8. 2012, pp. 43-47 .

[5] Miodragovic R., Djevic M. Cotemporary combine harvesters in corn harvesting. Annals of faculty of Igineering Hunedoarara, Tome IV, Fasiccole 3, 2006, pp. 199-206.

[6] Maertens K., Reyniers M., De Bardemaeker J. Design of a Dynamic Grain Flow Model for a Combine Harvester. Agricultural Engineering International: the CIGR Journal of Scientific Research and Development. Manuscript PM 01. 2005, vol. III. pp. 1-13.

[7] Mahmoudi A., Mirzazadch A., Abdollahpor S. Minimizing combine harvester rear losses by intelligent modeling of MOG ${ }^{1}$ passing concave. Elixir Agriculture. №52, 2012. pp.11397-11401.

[8] Evaluation Report. John Deere Sidehill 6600 Self-Propelled Combine. Prairie Agricultural Machinery institute, 1997, pp. 1-9.

[9] Laverda M400 Series. New Lewellinc consept. Publshed by New Holland Brand Communications. Bts Adv. Printed in Italy- 05/12.2012.

[10] Hyman et al. US Patent 4,557,276 A01F 12/32 Four way leveling mechanism for combine cleaning apparatus, 1985.

[11] Rowland-Hill et al.. European patent application 0178017 B1 16.04.86 Bulletin 86/16 Rowland-Hill, E. William Lateral leveling mechanism for combine cleaning apparatus, 1986.

[12] Alberic V. et al,. European patent application 0547036 B1 A01F 12/44 17.09.1997 Bulletin 1997/38. Combine harvester cleaning mechanism including grain pan and cleaning sieves.

[13] Desnijder et al., 1990. US Patent 4,897,071 A01F 12/44 Jan.30 / 1990. Combine harvester cleaning apparatus.

[14] Ященко Е.М., Песков Ю.А., Мещеряков И.К., Распопов А.Р., Водянникова Е.Ф., Кузнецов Н.Е. Устройство зерноуборочного комбайна для выравнивания по ширине зернового вороха на 
решете при работе на склонах (The device combine harvester for alignment width). Patent Russia, no. 2041594. 1995. (In Russian).

[15] Белинский А. и др. Кулачковое устройство зерноуборочного комбайна для динамического выравнивания слоя зернового вороха на очистке при работе на склонах (The cam device of a combine harvester for dynamic alignment of grain heap layer on cleaning when working on slopes). Patent Russia, no. 2521667. 2014. (In Russian).

[16] Vaiciukevicius E. et al., The cleaning of caucasian goat's rue chaff in the combine harvester cleaner. Agronomy Research 6 (Spesial issue). 2008, pp.405-413. 